\title{
DESCRIPTION OF DEVELOPMENTAL INSTARS OF BONOMOIA SIBIRICA SP. N. (ASTIGMATA: HISTIOSTOMATIDAE) WITH ECOLOGICAL OBSERVATIONS AND PHYLOGENETIC CONCLUSIONS
}

\author{
Stefan F. Wirth \\ Tyumen State University, Tyumen, Russia \\ E-mail: wirthstef@web.de

\begin{abstract}
Bonomoia sibirica sp. $n$. was reared under laboratory conditions in the original samples of bark beetle galleries together with several specimens of the Dendroctonus micans (Coleoptera: Scolytinae) beetle. Two types of samples were examined: the beetles taken from their hibernating galleries with some original substrate sticking to their bodies and the original bark pieces with corresponding soil from those galleries. Some mite protonymphs and tritonymphs appeared only in the soil remains on the bark beetle bodies, while the beetles themselves lacked mite deutonymphs; the collected bark contained also no mites. It is concluded that $B$. sibirica sp. n. needs to be in close contact with its carriers for a successful development. Since no males were found in the cultures of $B$. sibirica, it is assumed that these mites can reproduce by thelytoky. Under laboratory conditions, the deutonymphs preferred attaching to imagines of $D$. micans along the entire dorsal side of the elytrae. Furthermore, $B$. sibirica is one of a few Bonomoia species (including the species previously referred to genus Probonomoia) known from both, immatures and adults. Based on the morphological features of deutonymphs and adult females, $B$. sibirica sp. $\mathrm{n}$. is assumed to be a sister species of $B$. certa. It is discussed whether the known Bonomoia species, found in association with beetles of the taxon Scolytinae, might represent a subclade within Bonomoia.
\end{abstract}

KEY WORDS: Bonomoia, Bonomoia sibirica, Dendroctonus micans, Histiostomatidae, Scolytinae, deutonymphs.

DOI: 10.21684/0132-8077-2016-24-2-97-111

\section{INTRODUCTION}

The genus Bonomoia Oudemans, 1911 (Histiostomatidae, Astigmata), presently incorporating the genus Probonomia Fain et Rack, 1987, contained up to nine species distributed worldwide (Scheucher 1957; Wirth 2005 ). The type species of this genus, Bonomoia primitiva Oudemans, 1911, was described from a deutonymph.

Four previously known Bonomoia species and the new species described herein, Bonomoia pini Scheucher, 1957, B. spinifera Scheucher, 1957, B. certa Woodring, 1970, B. opuntiae Wirth, 2005, and $B$. sibirica sp. n., are known from deutonymphs and adults (Scheucher 1957; Wirth 2005). Among them, $B$. sibirica is the only species whose larvae, protonymphs, and tritonymphs are described in detail. The remaning Bonomoia species are known so far only from deutonymphs.

Since most histiostomatid species are described from deutonymphs, often due to the lack of living specimens suitable for a culture, in most cases only morphological characters were considered to be arguments for systematic statements. Thus, based on the phoretic deutonymph (hypopus), three genera, Bonomoia, Probonomoia, and Copronomoia Mahunka, 1976, were established to have a similar major character: eye-like organs are located anterolaterally on each dorsal side of the hysterosoma. According to our current understanding, the genus Bonomoia seems to be either identical to Probono- moia or contains some Probonomoia species, which do not necessarily represent a monophyletic clade (pers. comm., B. M. OConnor, Museum of Zoology, University of Michigan, Ann Arbor, USA). In contrast, the genus Copronomoia is considered to be different from Bonomoia (same comm.). The similar looking eye-like structures in Bonomoia and Copronomoia then may even be interpreted to have evolved convergently.

The function of the eye-shaped organs in histiostomatids is still unknown. Ultrastructural studies of these organs were performed by S. Wirth in cooperation with A. B. Shatrov (Zoological Institute RAS, St. Petersburg, Russia) for B. opuntiae. The results were difficult to interpret and have not yet been published. The author of this paper had performed behavioral experiments with deutonymphs of $B$. opuntiae, which indicated a more developed light-sensitiveness than in deutonymphs of other species without these well visible organs (Wirth 2005). These observations might indicate that these organs of Bonomoia might represent light-sensitive organs. $B$. opuntiae is a histiostomatid species that has been studied so far from several different perspectives. Thus, the behavior the prelarva performs to hatch out of its eggshell was shown (Wirth, 2006); molecular sequencing of this species was recently carried out in cooperation with M. Dabert (Adam 


\section{S. F. Wirth}

Mickiewicz University, Poznan, Poland, unpublished).

The exact habitats of most Bonomoia species are still unknown since only deutonymphs had been previously collected from their carriers. Bonomoia pini, B. spinifera, B. certa, and B. sibirica live in wooden habitats; some Bonomoia species are associated with bark beetles (Scheucher 1957). Bonomoia spharocerae Vitzthum, 1922 is associated with dipterans living in mammal dung (Scheucher, 1957), while adults of B. opuntiae and a similar undescribed species from the Galapagos Islands prefer rotting Opuntia plant tissue as a habitat (Wirth 2005, 2010a; Koller et al. 2012). Adults of $B$. opuntiae feed on microorganisms (Wirth, 2005, 2010a) and have a tolerance for very watery environments where adults can perform "swimming movements" (Wirth 2010a). Bonomoia opuntiae reproduces via thelytoky, while $B$. pini, $B$. spinifera, B. certa, and $B$. sp. (Galapagos Islands) were observed to produce males (Wirth 2005, Scheucher 1957; Woodring and Moser 1970).

In mouthparts of all known Bonomoia species, the distal digitus fixus of adults looks similar and appears more or less spoon-shaped (Wirth 2005). In $B$. opuntiae, these spoon-shaped distal ends of the chelicerae were observed to perform rotary motions against each other. By this way, food particles could be tightly grasped (Wirth 2005).

In the case when males exist, they possess a pair of distinct suckers laterally of the aedeagus (Scheucher 1957). This is considered being a plesiomorphic character, which might support the hypothesis that Bonomoia represents an early branch within the phylogenetic tree of the Histiostomatidae. In subsequent histiostomatids evolutions, these male suckers were completely lost in derived lineages (Wirth 2004). Dorsal setation in females of Bonomoia presents obviously a primeval character state among all Histiostomatidae. The symmetry and regular intervals between setae correspond more likely to related glandulate oribatid groups (Wirth 2004).

The present paper describes a new Bonomoia species, along with ecological and biological information on this species and considers the phylogentic relationships of bark- and wood-inhabiting Bonomoia species.

\section{MATERIAL AND METHODS}

About 30 individual adult beetles of Dendroctonus micans Kugel, 1794 (Scolytinae, Coleoptera) were collected out of their hibernating galleries under the bark of Pinus silvestris Linnaeus, 1753 (Pinoideae, Coniferales) in West Siberia, east of the city Tyumen $\left(56^{\circ} 35^{\prime} 11^{\prime \prime} \mathrm{N}, 67^{\circ} 42^{\prime} 55^{\prime \prime} \mathrm{E}\right)$, and placed alive into glass vials. The original substrate from the corresponding galleries was saved separately in plastic bags.

This material, taken from the hibernating nests of beetles, was transferred into four glass Petri dishes (10 $\mathrm{cm}$ in diameter), which were equipped with a layer of a slightly moist cell paper to support a suitable micro-climate, while the 30 collected beetles were kept alive in their original vial in a refridgerator $\left(4^{\circ} \mathrm{C}\right)$ for about ten days. The beetles were observed by random examination for phoretic mites. No substrate was added to these vials, thus the beetles had direct body contacts to each other and were surrounded only by their excrement and some gallery substrate particles, stuck to their cuticle during the collection process.

After ten days, the living beetles were examined for phoretic histiostomatids using a stereo microscope by holding the live beetles carefully with fingers or with fine tweezers; afterwards these beetles were released into a selected number of Petri dishes, which contained the original gallery substrate, in order to create near-natural ecological conditions. The Petri dishes were placed directly after the sampling excursion into a bigger plastic container $(20 \times 40 \mathrm{~cm})$, covered with a plastic lid and equipped with holes to guarantee air ventilation inside the container. The container was kept at room temperature (Tyumen, Russia, April 2015, about $20^{\circ} \mathrm{C}$ ). This way, the substrates without beetles were examined for the presence of histiostomatids. The beetles then, after ten days, were distributed into four out of the eight Petri dishes with the gallery substrate inside, with about seven individual beetles per dish. The cell paper was moistened twice a week (about 10 water droplets per dish). The bark pieces as well as the bore dust created by the beetle activities were in the meantime never directly sprinkled. The remaining four Petri dishes without beetles were kept as controls, whether histiostomatids would appear inside in the absence of beetles.

Peeled potato pieces were added to each of those dishes (always 4 pieces, cubes 10x10 mm). They were moistened with water droplets as often as necessary until the decomposition processes occured. Thus, bacteria growth was stimulated as a possible food for histiostomatid mites. 
Specimens of $B$. sibirica sp. n. were cleared with $80 \%$ lactic acid $\left(48\right.$ hours at $40^{\circ} \mathrm{C}$ ), and after that, they were fixed with $70 \%$ ethanol and mounted on slides using Hoyer's medium. Photographs of the mounted individuals were taken using the DIC contrast option of a Leica microscope. Video footage was recorded using a camera connected to a Zeiss stereomicroscope.

The nomenclature of the body setation generally follows that of Griffiths et al. (1990). Exceptions include the names for dorsal setae of the proterosoma and of ventral coxal setae situated anterior to the anus, respectively suckerplate. They follow Bongers et al. (1985) and correspond to the nomenclature of Griffith et al. (1990). This older nomenclature is retained because it formally indicates the position of these setae better than the newer version. The three-digit letter combination of proterosomal setae differs clearly enough from the two-digit combination for the hysterosoma setation. The ancient Roman letters in the names of the ventral setation emphasize clearly that this nomenclature refers to their positions close to the walking legs I through IV.

\section{SYSTEMATICS}

Family Histiostomatidae Berlese, 1897

\section{Genus Bonomoia Oudemans, 1911 Bonomoia sibirica sp. $\mathbf{n}$.}

Figs. 1-10

Description: Differential diagonosis. Bonomoia sibirica sp. n. is morphologically and ecologically most similar to $B$. certa. Both species share the following characters differentiat-

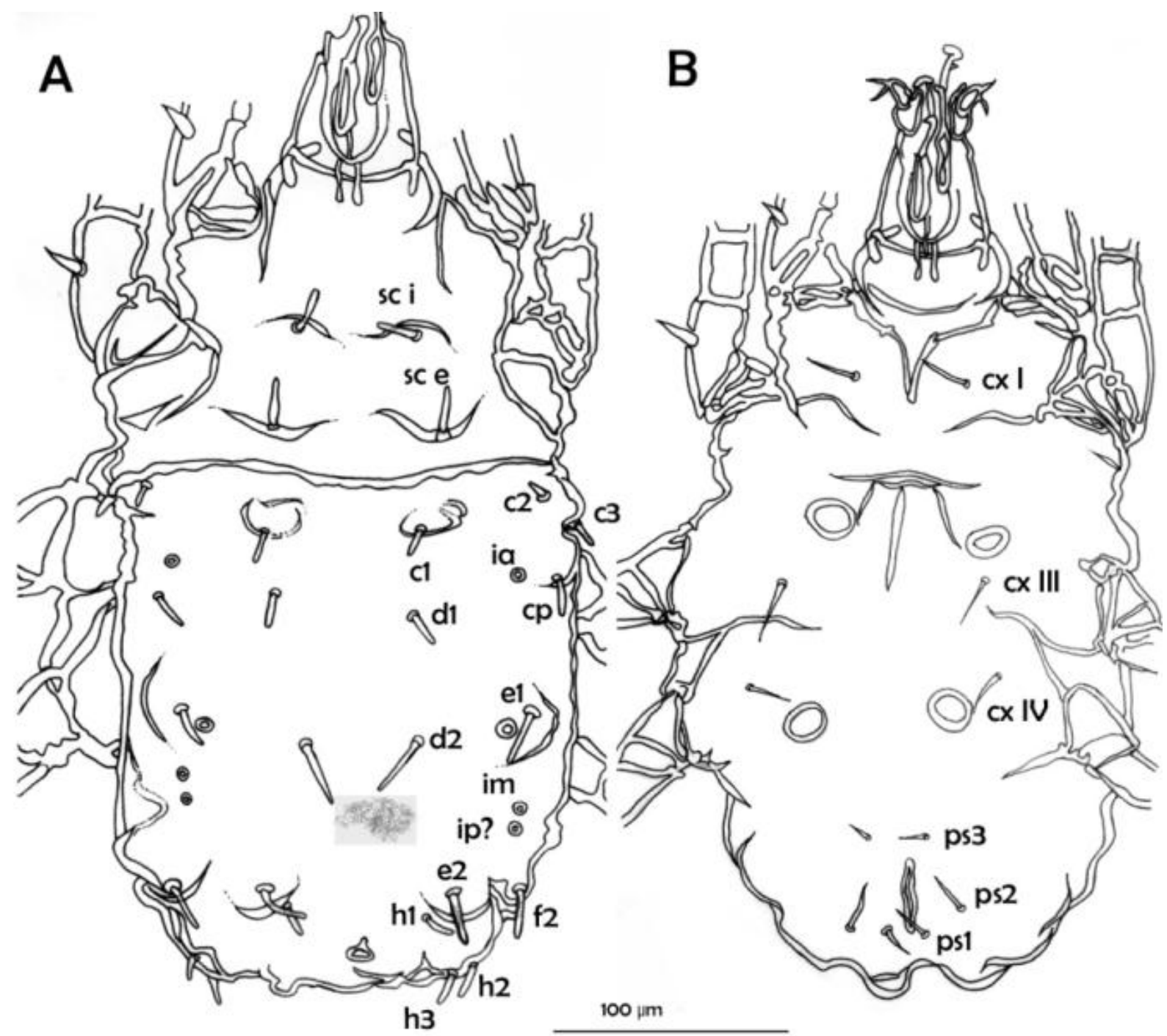

Fig. 1. Female of Bonomoia sibirica sp. n., A-dorsal, B-ventral view. The greyish area on the posterior dorsal hysterosoma indicates the smoothly dotted cuticle on the whole dorsum. Opisthonotal gland opening is located posteriorly of setae $e 1$. 


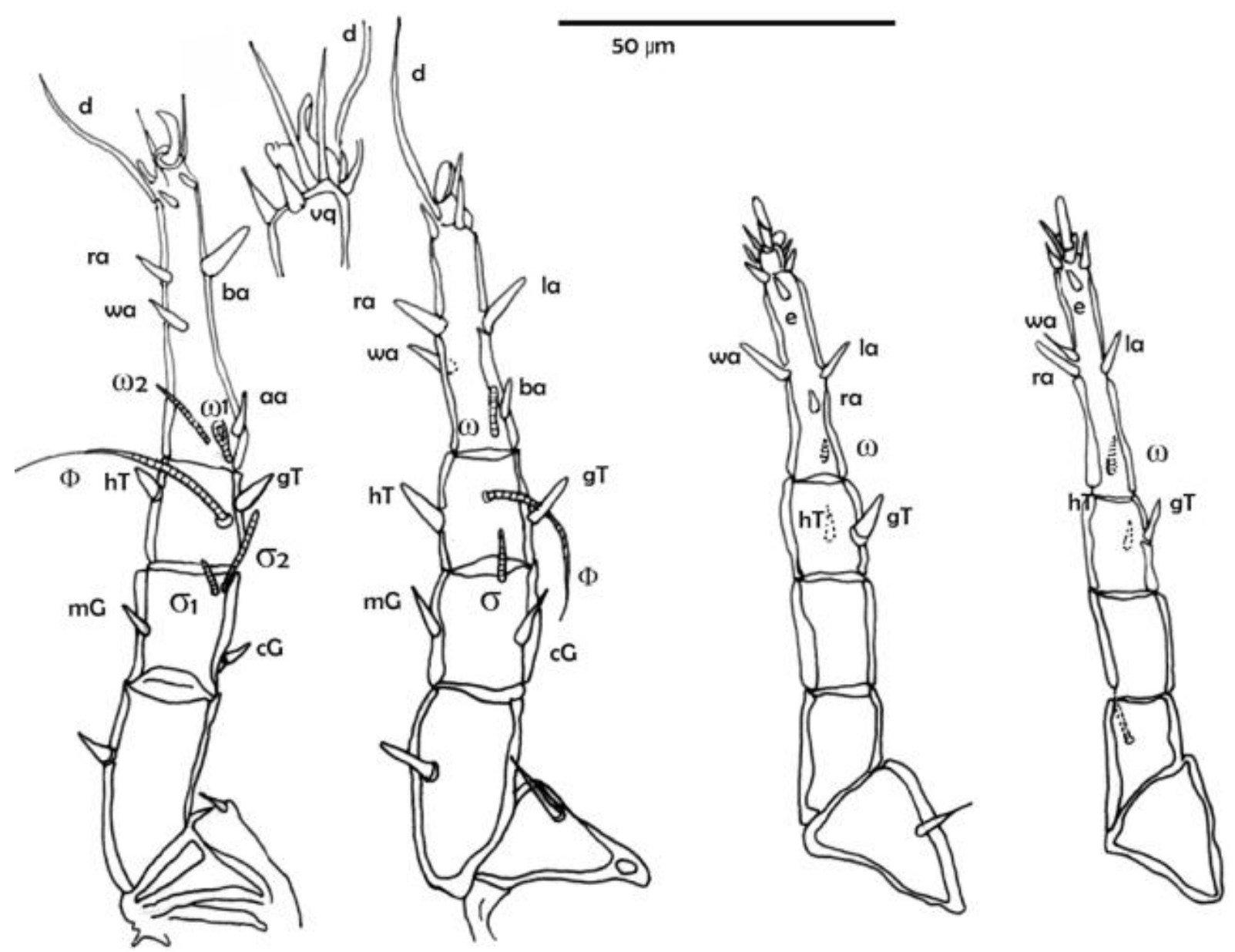

Fig. 2. Legs of a female of Bonomoia sibirica sp. n., ventral view, legs of the left side.

ing them from all other known Bonomoia species.

Female: the body outline is compact, with the lateral margins running almost parallel to each other. The distal end of digitus fixus of the chelicera is shaped like an arrow with two ventrally elongated lobes. A medianly directed thorn posteriorly to the arrow exists. The patterns of dorsal setation are similar. Dorsal setae $s c i, s c e, c 1, f 2, h 1$, and $h 2$ are situated on cuticular humps. The opisthonotal gland openings are situated posterolateral to corresponding setae $e 2$. The ventral ring organs are arranged in a similar pattern and shaped as slightly elongated oval (anteroposteriorly flattened rounded structure). Ventral setae $p s 3, p s 2$, and $p s 1$ are in a similar arrangement around the anal opening (Fig. 1).

Deutonymph: the palposoma is short and not protruding anteriorly beyond the margin of the dorsal proterosoma shield. The patterns of ventral apo-demes are shown in Fig. 3.

Bonomoia sibirica differs from $B$. certa in having the following characteristics. Female: dorsal setae are rod- or even cudgel-shaped. Setae $d 2$ and el are situated on a flat cuticle, not on tubercles. Tubercles bearing setae sci and sce are similar in size. Setae $e 1$ are longer than all other dorsal setae of proterosoma and hysterosoma. The distal part of the digitus fixus of chelicera has a second thorn pointing laterally. The palparmembrane is of a complex form, surrounding the distal pedipalp article both, dorsally and ventrally (see chapter morphology of the gnathosoma). The pattern of ventral setation anteriorly of the anus is different (setae $p s 1$ and ps3 are situated close to the midline near the anuslevel, while setae $p s 2$ are positioned distinctly more lateral). The posterior ring organs are anteroposteriorly flattened as in B. certa, but their outer ends are slightly turned caudally (Fig. 1). Deutonymph (Fig. 3): the body shape is noticeably wider than in B. certa. The dorsal cuticle of hysterosoma is sculptured laterally with smooth wrinkles (reminding that of $B$. pini, but much lesser developed and covering only a part of the dorsal surface).

Female. Length $320 \mu \mathrm{m}(\mathrm{n}=1$ paratype; measured medianly from anterior margin of proterosoma to posterior margin of hysterosoma). Gna- 

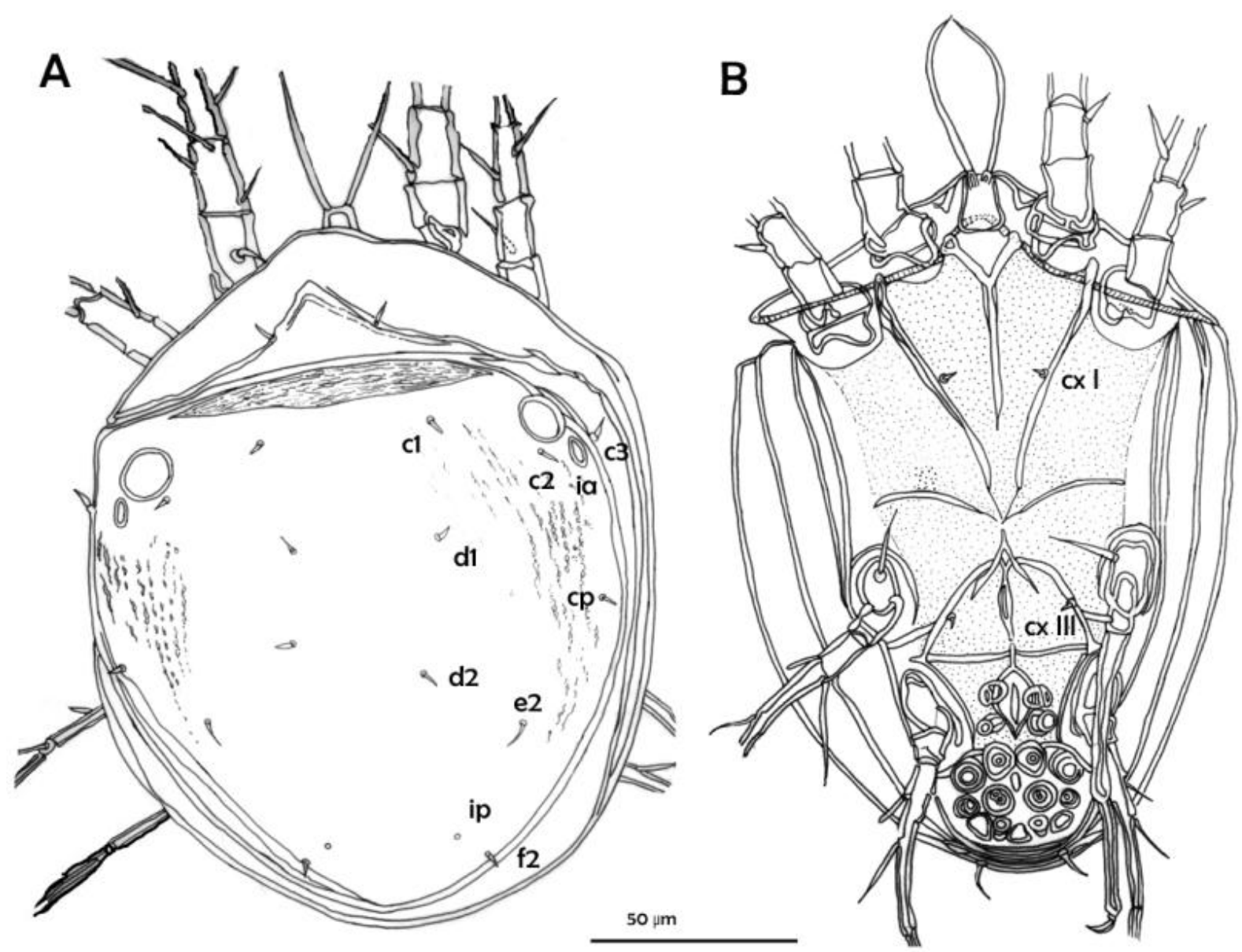

Fig. 3. Two individual deutonymphs of Bonomoia sibirica sp. n.; A—dorsal view, B-ventral view.

thosoma elongated, distal pedipalpal articles slightly bulged laterally (Fig. 10A). Distal digitus fixus of chelicera scraper-shaped and elongated ventrally. Two thorn-like extensions posteriorly to distal ending of chelicerae present, one pointing medially, other pointing laterally (Fig. 9A). The shape of hysterosoma almost rectangular. Setae of dorsal proterosoma and hysterosoma short, as typical for most histiostomatid species, strongly sclerotized and stick-shaped. Setae $d 2$, $e 1, e 2$, and $f 2$ elongated related to other dorsal setae of hysterosoma ( $d 2$ almost twice as long as $d 1$, other named setae about 1.5 times as long as d1). Setae $s c i, s c e, c 1, c 3, c p, e 1, e 2$ and $f 2$ on top of humps. Setae $h 2$ and $h 3$ on same upheaval. Opisthonotal gland openings clearly visible and located posteriomedially to seta $e 1$. Cupules $i a$ medially to setae $c p$, cupules $i m$ and $i p$ (unclearly visible) located close to the lateral margins of hysterosoma, being arranged in a longitudinal row between bases of setae $e 1$ and $f 2$. Copulatory opening medium sized (about twice as wide as seta $e 2$ ). Cuticle smooth, sculptured by a dotting (Fig. 1A).
Ventral setation well visible; setae $c x I, c x I I I$, $c x I V$, and $p s 2$ thin and tapering, almost of similar length $(c .20 \mu \mathrm{m})$. Setae $p s 3$ and $p s 1$ shorter (ca. $12-15 \mu \mathrm{m})$. Seta $c x$ III located posteriorly to posterior ring organ and anterior to posterior apodeme of leg III, and seta cx IV anteriolaterally to posterior ring organ. Ring organs almost of the same size and arranged along the same longitudinal line. Both ring organs ovate, outer ends of anterior organs turned slightly anteriorly, outer ends of posterior organs slightly turned posteriorly. Length of longer diameter of ring organs about $10 \mu \mathrm{m}$. Vulva transverse as in all Histiostomatidae (length $c .22 \mu \mathrm{m}$ ). Longitudinal apodeme posterior of vulva well visible, with length $c .15 \mu \mathrm{m}$ (Fig. 1B).

All legs (Fig. 2) about $120 \mu \mathrm{m}$ long (measured from proximal part of trochanter). Legs I and II wider than legs III and IV. Legs I: setae $c G$ and $m G$ almost of same length, short, and strongly sclerotized; solenidion $\Phi$ distinctly elongate; solenidia $\omega 1$ and $\omega 2$ in usual arrangement and shape, close to proximal margin of tarsus. Legs II: setae $g T$ and $h T$ clearly visible and thin, with $g T$ slightly longer than $h T$. Legs III: seta $e$ thick and strongly sclero- 


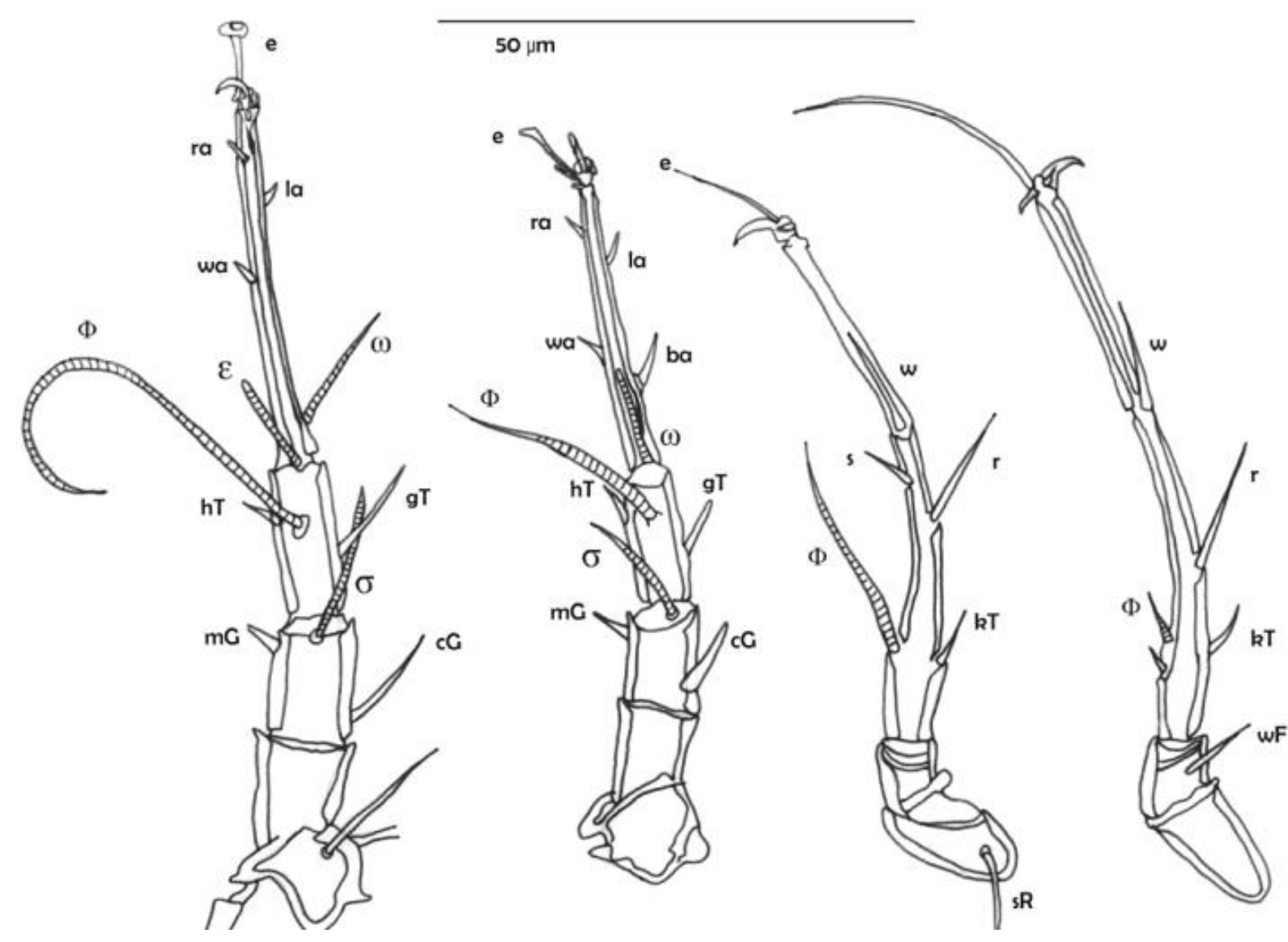

Fig. 4. Legs of a deutonymph of Bonomoia sibirica sp. n., ventral view, left side.

tized. Solenidia $\Phi$ and $\sigma$, and setae $m G$ and $c G$ absent or lost in the studied specimens. Legs IV: seta $e$ thick and strongly sclerotized. Solenidia $\Phi$ and $\sigma$, and setae $m G$ and $c G$ absent or lost in the studied specimens (Fig. 2).

Male: unknown.

Deutonymph. Length $140 \mu \mathrm{m}(\mathrm{n}=3$ paratypes; mean and range: $140.0 \mu \mathrm{m}(140.0-140.0) \mu \mathrm{m}$; measured: medianly from anterior margin of proterosoma to posterior margin of hysterosoma). Gnathosoma (=palposoma) not overmounting anterior margin of proterosoma (Figs. 3A, B). Length of palposoma (measured medianly, ca. $12 \mu \mathrm{m}, \mathrm{n}=1$ specimen), twice as long as wide at its distal margin. Lateral and terminal setae of palposoma directed in different optical levels: terminal (distal) setae distinctly directed dorsally with complex shaped sockets, lateral setae hardly visible and slightly moved ventrally, thin and fragile (Figs. 5A, B). Dorsal hysterosoma (measured medianly) almost as long as wide in its anterior region (measured anteriorly to eye-like structures). Only one pair of setae representing sci on dorsal proterosoma visible, setae sce (expected posterior and more laterally) invisible in all studied specimens. All other dorsal setae short and almost of similar length. Eye-like organs located anterolaterally on hysterosoma, right anteriorly to seta $c 2$. Cupules $i a$ and ip well visible: ia slit-shaped, orientated longitudinally, and placed between bases of setae $c 2$ and $c 3$, posterolateral to eye-like organs. $\mathrm{Cu}-$ pules ip located medially to setae $f 2$, rounded and small in size. Seta $h l$ absent or lost in all studied specimens. Cuticle slightly sculptured along lateral margins of hysterosoma, wrinkled and partly dotted (Fig. 3A).

Most parts of coxal fields I, II, III, and VI stronger sclerotized than rest of ventrum (dotted in drawing Fig. 3B). Setae $c x$ I and $c x$ III very short, not conoid-shaped. Sternal apodeme ending free posteriorly to setae $c x$ I. Apodemes posteriorly to legs I and respectively anteriorly to legs II with strongly sclerotized part and thin and line-shaped areas. Line shaped areas touching apodemes anteriorly to legs III. Apodeme anteriorly to legs III bulged towards midline and consisting mostly of a strongly sclerotized structure, only median area being fragile, thin or line-shaped, touching apodemes anteriorly to legs II (Fig. 3B). Sucker plate well developed (Fig. 3B), all its structures clearly visible. Longitudinal diam- 


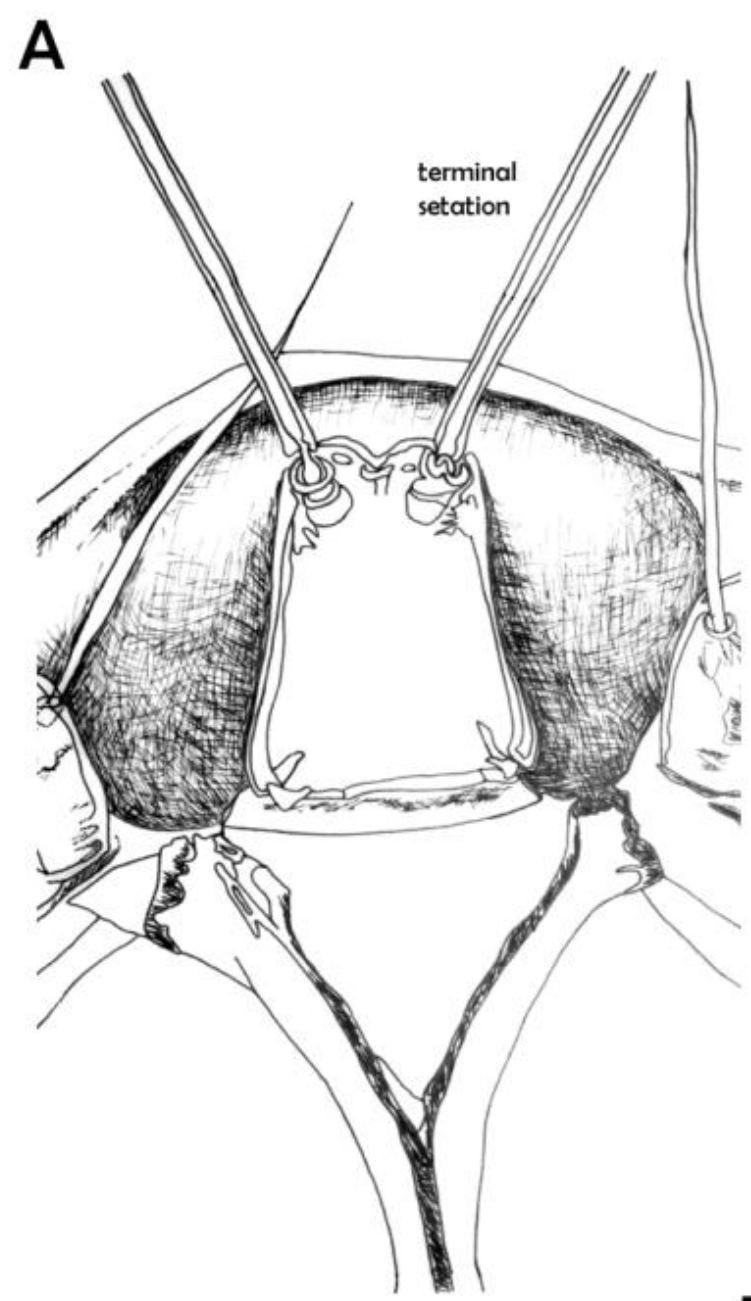

B

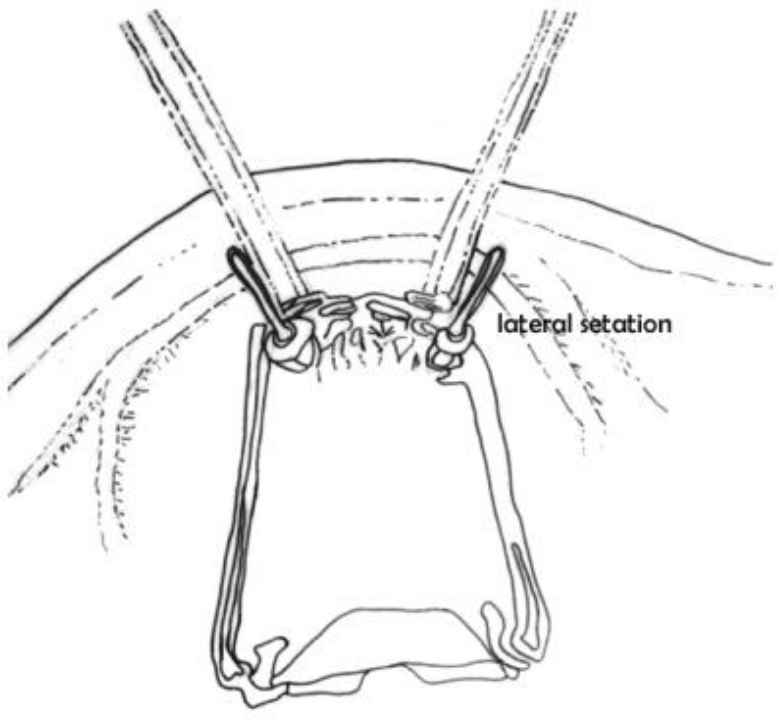

Fig. 5. Palposoma of a deutonymph of Bonomoia sibirica sp. n.; A—dorsal view, B—ventral view.

eter (measured medianly) about two thirds as long as its width at greatest part (measured at level of anal opening). In addition to suckers and conoids, in total 5 suckerplates are visible, as well as one anterior and 3 posterior ones (Fig. 3B).

Leg I about $100 \mu \mathrm{m}$ long ( $\mathrm{n}=3)$, legs II, III and IV of about $80 \mu \mathrm{m}(\mathrm{n}=3)$. Trochanter of leg I equipped with clearly visible seta $p R$ being distinctly elongated and usually directed medially. Solenidion $\Phi$ of tibia I $50 \mu \mathrm{m}$ long (n=3), with curved distal end. Modified seta $e$ of tarsus I with small distal lobe (Fig. 4). Solenidion $\Phi$ on tibia III distinctly elongated and extending slightly beyond seta $s$ of tarsus I. Setae $w$ of tarsi III and IV half as long as the distance between their bases and corresponding tarsal apices.

Tritonymph ( $\mathrm{n}=1$, paratype); the specimen is represented by an adult female in quiescent state covered by the tritonymphal cuticle; all tritonymphal structures well visible except for the posterior part of hysterosoma with anal opening and anal setation, which are completely missing-Figs. 6A, $\mathrm{B}, 10 \mathrm{~B})$. Length including hindpart of adult female (border between female and tritonymph in this area not visible) $240 \mu \mathrm{m}$ (measured medianly from anterior margin of proterosoma until posterior margin of hysterosoma). Gnathosoma as in adult female. Dorsal seta sci on socket-shaped pedestal, seta distinctly bent to midline. Setae $s c i$ and $s c e$ on common cuticular shield. Posterior part of that shield with two vaulted cuticular extensions directed posteriorly and bearing seta sce (Fig. 6A).

Setae $c 1, c 2, d 1, e 1, h 2$, and $h 3$ situated on cuticular bumps. Setae $c 3$ and $h 1$ invisible or lost in the studied specimen. Seta $e 2$ of left side invisible (Fig. 6A). All dorsal setae almost of the same length, shaped similarly to those in the female.

Ventral apodemes $c x I, c x I I I$, and $c x I V$ with pointed tips. Seta $c x I I I$ posteriorly to anterior ring organ, seta $c x I V$ anteriorly to posterior ring organ. Ring organs almost perfectly rounded with posterior ring organs slightly smaller than anterior ones. 


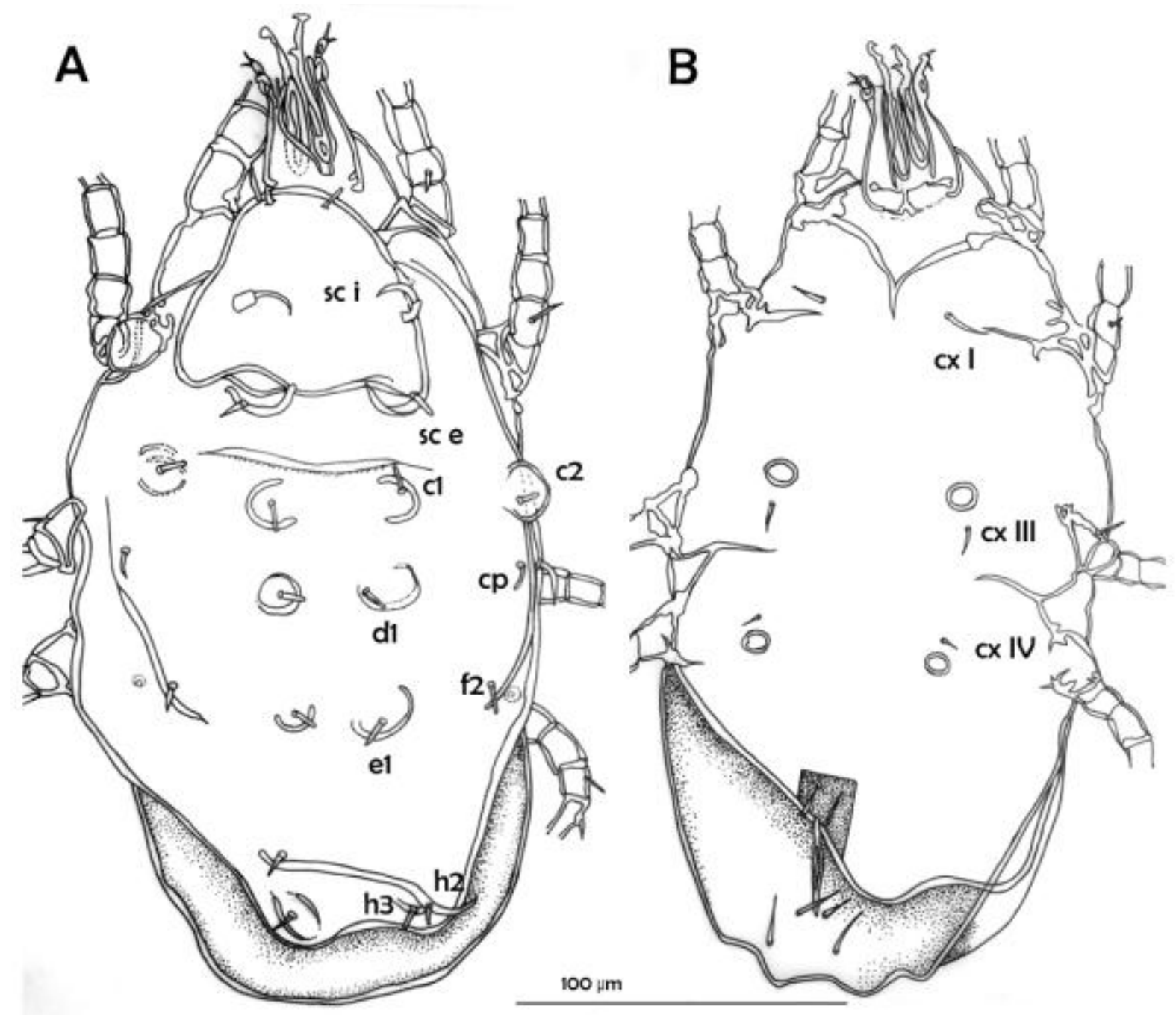

Fig. 6. Tritonymph of Bonomoia sibirica sp. n.; it represents a reconstruction as the only available specimen is a quiescent adult female inside the tritonymphal cuticle. The posterior area shows the hind body of the hatching female, thus the posterior end including the tritonymphal anal opening is destroyed and unavailable. A-dorsal, B-ventral view.

Opisthonotal gland opening situated lateral to seta $f 2$ (Fig. 6B).

Protonymph. Length $190 \mu \mathrm{m}$ (mean and range of one holotype and two others specimens $190.0 \mu \mathrm{m}(190.0-190.0) \mu \mathrm{m}$; measured medianly from anterior margin of proterosoma to posterior margin of hysterosoma). Shape of gnathosoma as in female (Fig. 9A, B). Dorsal setae of almost same length (ca. $3.2 \mu \mathrm{m}$ ), short and with a pointed apex. Setae $s c e, c 1, c 2, c 3, d 1, e 1, f 2$, $h 1, h 2$, and $h 3$ arranged on cuticular bumps. Setae el share same median bump; all other dorsal setae on single bumps. Opisthonotal gland openings posterior to setae $f 2$. Dorsal cuticle sculptured by dotted areas, mostly along lateral and posterior areas of proterosoma and hysterosoma (Figs. 7A, 10C).
Ventral setation well visible, $c x I$ and $c x I I I$ as well as $p s 1, p s 2$, and $p s 3$ with pointed apex and with length as in female. Seta $c x I V$ distinctly smaller than all other ventral setae (about $40 \%$ of their length). Seta $c x I V$ located anteromedially to ring organ (Fig. 7B).

Ring organs oval-shaped, inner ends slightly turned anteriorly remaining in position to the posterior ring organs of the female. Ring organs located at level of posterior apodeme of leg IV (apodeme in the specimen of Fig. 7B only visible on the right side).

Larva. Length $90 \mu \mathrm{m}(\mathrm{n}=1$, paratype; measured medianly from anterior margin of proterosoma until posterior margin of hysterosoma). Dorsal setation short, with pointed apex. Setae el slightly longer than others. Setae sce and $c 1$ lo- 


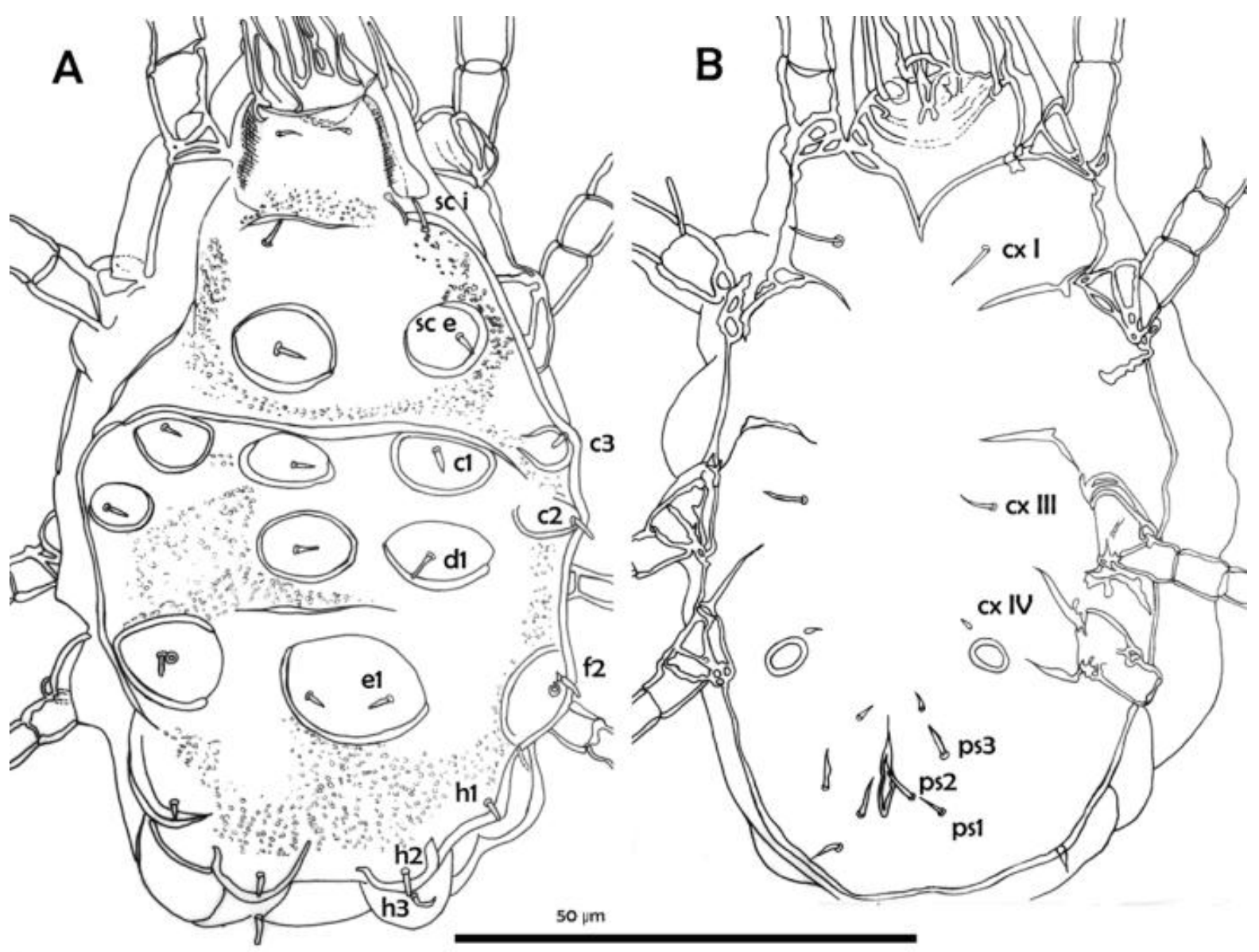

Fig. 7. Protonymph of Bonomoia sibirica sp. n.; A—dorsal, B-ventral view.

cated on cuticular bumps, similar to those in other developmental stages. Setae $c 2, d 1, f 2, e 1, h 2, h 1$, and $h 3$ on cuticular shields as typical for larvae of the genus Histiostoma. Pairs of setae $d 1$ and $e l$, each arranged on common median shield. Setae $c 3$ lost in studied specimen or absent (Fig. 8A).

Ventral setae $c x$ I and $c x$ IV well visible, with pointed apex and length being similar to those in protonymph and female. Setae cxIII invisible. Pseudanal setae $p s 1, p s 2$, and $p s 3$ of nearly identical lengths and distinctly shorter than setae $c x \mathrm{I}$ and $c x$ IV. Seta $c x$ I anteromesal to Claparede's organ. Claparede's organ ovate, similar in size and form to ring organs and located anterioral to legs II, almost touching apodemes II (Fig. 10D). Apodeme I extending to midline and fused into a wide Vshaped structure (Fig. 8B).

Egg: unknown

Type material. One protonymph as holotype, 1 larva, 3 deutonymphs, 1 tritonymph, and 1 female as paratypes collected and reared from bark galleries of Dendroctonus micans (Coleoptera: Scolytidae), Russia, Tyumen Province, East of Tyumen, $56^{\circ} 35^{\prime} 11^{\prime \prime} \mathrm{N}, 67^{\circ} 42^{\prime} 55^{\prime \prime} \mathrm{E}$, April 2005, colls. S. Wirth and A. Khaustov.

Depository. One protonymph as holotype (slide number: 7078) and two deutonymphs as paratypes (slide numbers: 7079, 7080) are deposited at the Moravian Museum, Hviezdoslavova 29a, CZ-627 00 Brno, Czech Republic; remaining paratypes are in the private collection of S. Wirth.

\section{Morphology of the protonymph gnathosoma}

The gnathosoma of all free-living instars of B. sibirica is similar. The mouthparts of the protonymph were analyzed using a Leica transmission light microscope with DIC contrast. A comparison with other Bonomoia species was impossible, because mouthparts of other species have never been studied in detail. A very complex distal area of the gnathosoma was found in Bonomoia opuntiae (Wirth, 2005). In B. sibirica sp. n., membraneous structures, named palparmembrane, cover the distal and ventral sides of pedipalpal article in a threedimensionally complicated arrangement, as it was 


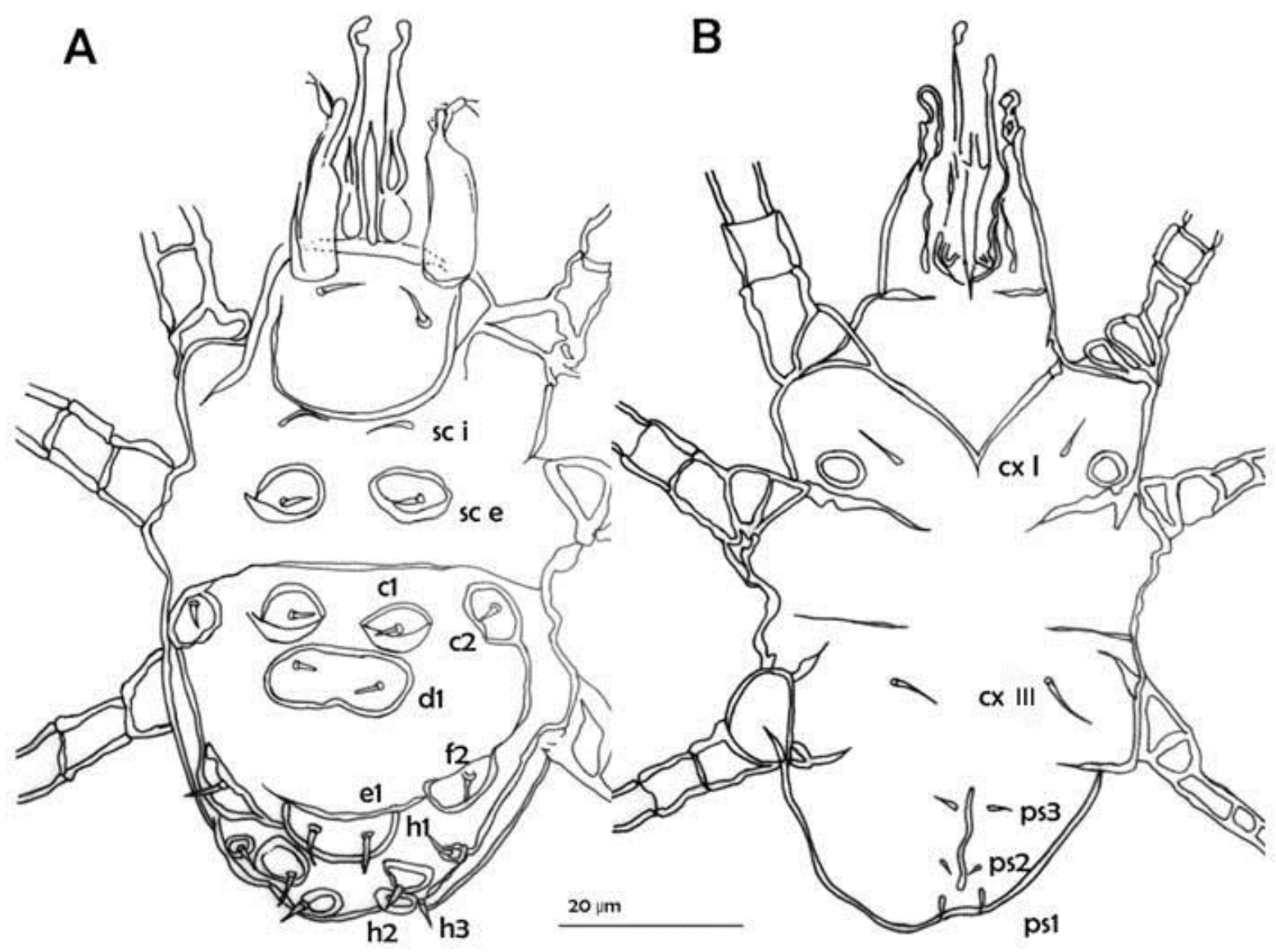

Fig. 8. Larva of Bonomoia sibirica sp. n.; A—dorsal, B-ventral view.

shown for $B$. opuntiae. In detail, these structures differ in B. opuntiae and B. sibirica.

The morphology of protonymphal gnathosoma (Figs. 9A, B) in B. sibirica sp. $\mathrm{n}$. is as follows. The length of the whole gnathosoma is about $35 \mu \mathrm{m}$. The shape of the distal digitus fixus is as explained in the description of female (see above). Gnathosoma in Fig. 9 is displayed in isometric projection. Gnathosoma appears elongated due to the distal pedipalps directed slightly forward; these distal pedipalps are slightly bulged laterally. Digitus mobilis as for other histiostomatids is reduced to a vestigial structure. The left digitus mobilis depicted in Fig. 9A in a dorso-lateral view (almost laterally) consists of two major parts: 1) a massive anterior area, divided into a downward directed hook-shaped structure and a closely connected anterior snailshell-shaped part; 2) a thinner posterior area with a "fringed" ventral edge. A torus belonging to the massive anterior area forms the dorsal edge, which is connected with the main branch of the chelicera (Fig. 9A).

The palparmembrane represents anterior elongations of the coxal endites (Wirth 2006b). Lobes of palparmembrane cover the two distal pedipal- pal articles from ventral and dorsal sides and shape two conspicuous lobal folds directed medially (both obviously originating dorsally): one bigger fold at the dorsal level of the distal pedipalpal article (underneath of the chelicera, right pedipalp in Fig. 9A) and a second smaller one at the level of the cheliceral guiding structures (smaller fold, not visible in the reconstruction). The distal pedipalpal article has a lateral palparmembrane lobal extension. Same lobal elongation runs laterally towards the proximal pedipalp article where it is divided into at least three "sub-lobes" (Fig. 9A, right and left side). A membrane extending dorsally at the level of the second pedipalp article forms a "double-fold "(Fig. 9A, left side, black area of distal pedipalp articles indicates an optical section through the pedipalp itself).

Ventral gnathosoma (Fig. 9B): coxal endites form, as in all histiostomatids, a lobal fold on both sides, being in $B$. sibirica sp. n. conspicuously turned laterally in its distal part. Ventral lobes are peak-shaped (Fig. 9B). Medianly visible fused lateral lips are complex-shaped and have in their median part a serrated area on both sides (Fig. 9B). 

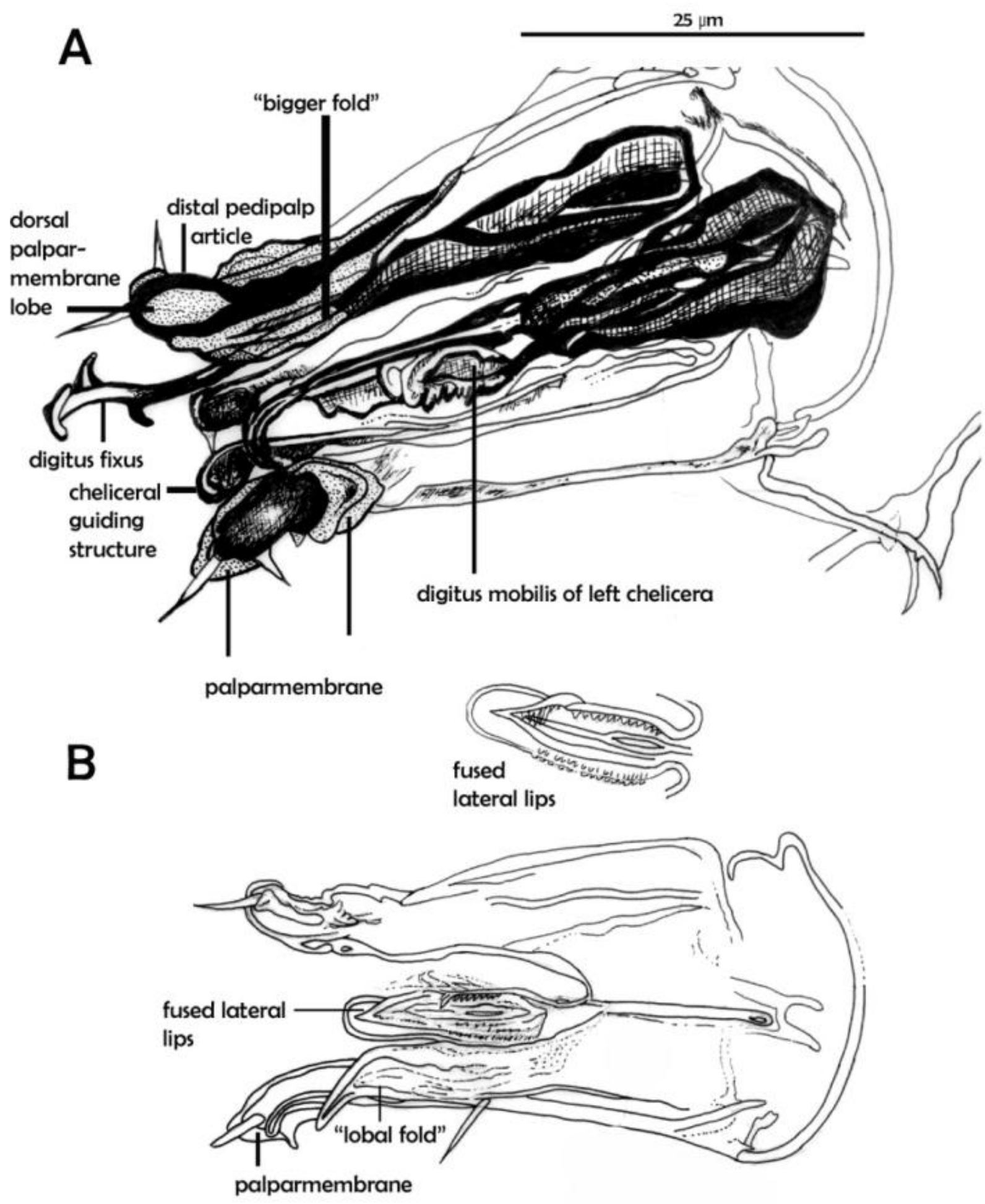

Fig. 9. Gnathosoma of Bonomoia sibirica protonymph. A-Three-dimensional reconstruction by overlapping drawings of different optical section levels with each other of the median area of the gnathosoma in a dorso-lateral view. Left and right pedipalps show different focal levels, dotted areas - distal palparmembrane, darker areas - cuticle of the pedipalp articles, left chelicera - the complex digitus mobilis (reduced to vestigial structures) visible in lateral view. $\mathrm{B}$ - a section of the ventral gnathosoma, the fused lateral lips are depicted in an isolated drawing.

\section{Biological observations under laboratory conditions}

Adult beetle specimens of $D$. micans did not carry any phoretic mites. Also the superficial ran- dom examinations ( $\mathrm{n}=15$ beetles inside their vials) of the beetles directly after the excursion did not indicate any phoretic mite stages attached to their surface. All samples with gallery substrate, but 

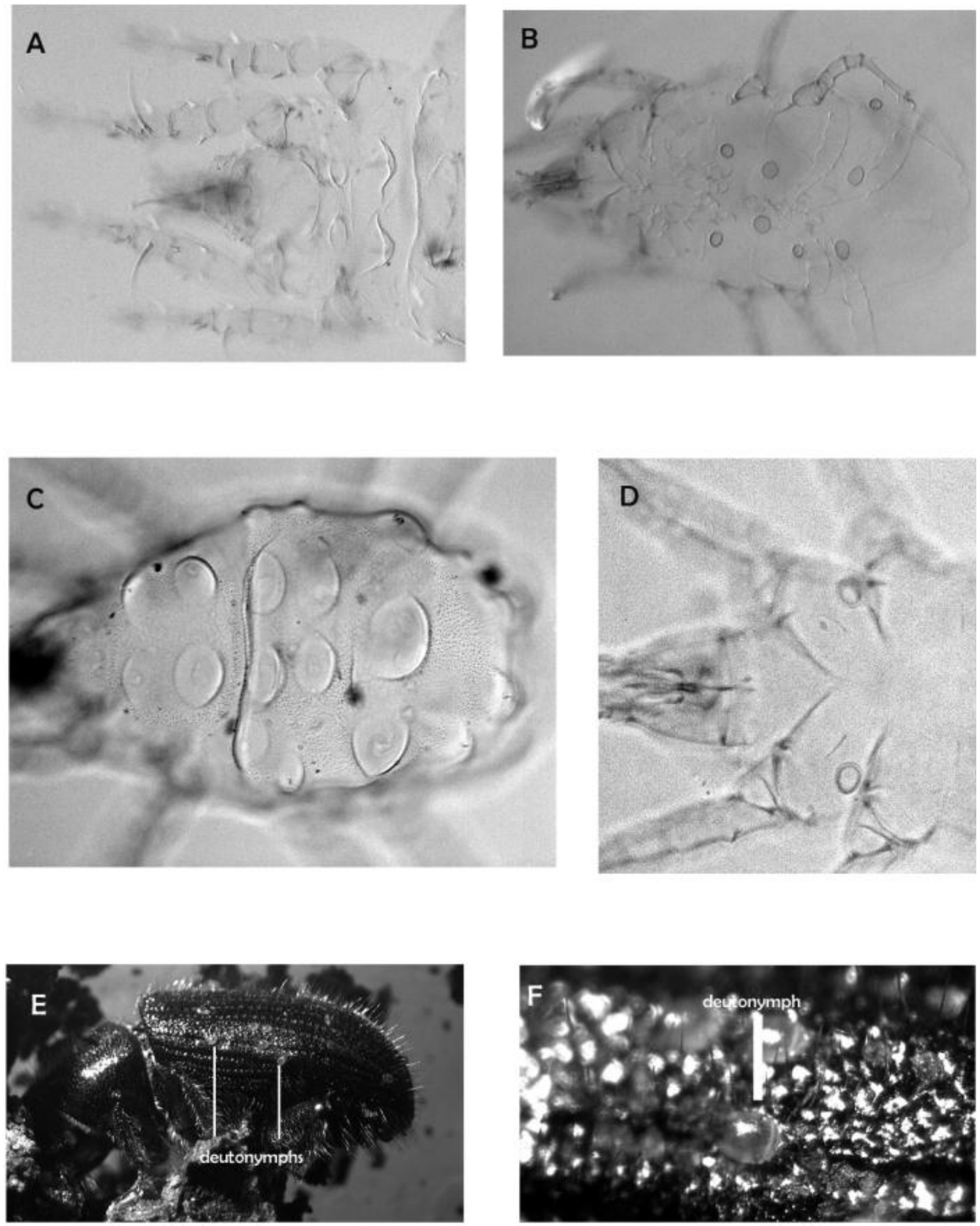

Fig. 10. Bonomoia sibirica sp. n.; A-anterior area of female, dorsal view B-female inside the tritonymphal cuticle, ventral view C-protonymph, dorsal view, D-anterior area of larva, ventral view D-lateral view of Dendroctonus micans with deutonymphs on elytrae, E-deutonymph attached to the elytra of D. micans, higher magnification.

without beetles, had no presence of histiostomatids at all. Developmental stages (protonymphs and tritonymphs) of $B$. sibirica sp. n. were only discovered inside the vials with beetles from the refrid- gerator. The mites developed on a small number of tiny soil particles, which were partly sticking to the beetles. This apparently means that $B$. sibirica $\mathrm{sp}$. n. could not be cultured under laboratory condi- 
tions. Single specimens could be reared as long as D. micans beetles remained alive. The mites went through two generations within 2.5 weeks and produced very few adults. Most individuals of the first generation developed into deutonymphs in a greater number and remained in that stage. Then these deutonymphs attached themselves to the beetles (Figs. 10E, F). In dishes with gallery samples, but without beetles, no histiostomatids developed at all.

The developing $B$. sibirica sp. n. specimens required rather dry conditions (no visible moisture film) and did only grow on bark substrate, which stayed in the direct contact with tiny soil pieces, which had stuck to the formerly isolated beetle specimens. The mites did not switch over to neighboring bark pieces, collected from the original galleries, which had neither Bonomoia specimens from the beginning on, nor did they develop on slightly moistened potato pieces, which were added to stimulate the microorganism growth. On their limited preferred substrate, the mite specimens only rarely appeared on the surface of the wood, unlike other wood inhabiting histiostomatids under laboratory conditions. They instead inhabited small fissures and beaks and developed inside the bark particles. They completely died out when the beetles died. The exact food source of mites still remains unknown. When mites were observed actively walking along the surface of their microhabitats, they performed almost permanent chelicera movements and often had their gnathosomas touching the ground as it is known for bacteria feeding histiostomatid species.

Males were not found. It is not known whether females reproduce only thelytokously, or whether males were so rare that they were overlooked.

\section{Attachment area of deutonymphs on beetle carriers}

The beetles of $D$. micans collected from the field had no phoretic mites attached to their bodies at all. The soil stuck to isolated beetles contained numerous mite protonymphs and a few tritonymphs (about 30 to 50 individuals), which were at the time of the experiment not mounted on slides and used instead for rearing purposes. Most of the protonymphs either developed directly into deutonymphs or reproduced as adults, and their offspring then remained mostly in the deutonymphal stage.

They all attached themselves to the present beetles in great numbers. The individual beetles were covered with 30-40 deutonymphs, which seemed to prefer (more or less strictly) the dorsal elytrae as attachment areas (Figs. 10E, F). They did not seem to be disturbed by the elytral setation of the beetles. Deutonymphs seem to distribute themselves symmetrically on both sides of a beetle, but this was not closely studied nor statistically proved. They regularly detached themselves from their places and re-attached again somewhere else, especially when they were disturbed by the observation process.

It is unknown whether deutonymphs also attached to the areas under the elytrae. Freshly dead cadavers, which still had living deutonymphs on their surfaces, were completely dissected on a random basis ( $\mathrm{n}=5$ beetle specimens). No phoretic mites were found under their elytrae.

\section{DISCUSSION}

\section{Morphology and biology}

The mite species could not be reared under laboratory conditions, as for example described for B. opuntiae in Wirth (2005). As it was found, single specimens inside their original habitats only survived until the corresponding beetles remained alive, and the researchers assumed that the presence of the beetle $D$. micans is important for the mite's survival. Chemical excretions or the excrements of the beetles themselves might create a microclimate being necessary for the development of mites. Scheucher (1957) noted that several histiostomatid species require very specific conditions that cannot easily be imitated by laboratory conditions. According to Wirth and Moser (2010), the mite Histiostoma blomquisti could not be reared under laboratory conditions, although the deutonymph on living ant queens could be kept alive for months. Mites seemed to feed on bacteria. Obviously, there is no flexibility of the mites for all kinds of existing bacteria .

The collected beetles originally had no deutonymphs attached; instead other developmental stages of $B$. sibirica were available in substrate particles, which were stuck to isolated beetles. Thus one might ask whether D. micans indeed represents the original phoretic carrier. There are known cases in which mite species, living in bark beetle substrate, can be carried by different arthropods (Wirth 2012). Although there was correlation between the survival of beetles and of mites observed, it is unknown whether $D$. micans is the only phoretic carrier of $B$. sibirica. As there were no males found, it is assumed that females can successfully 


\section{S. F. Wirth}

reproduce thelytokously as in $B$. opuntiae (Wirth 2005).

The pattern of dorsal setation in females of $B$. sibirica corresponds to that in other known adults of Bonomoia species. It obviously represents a phylogenetically older pattern, in which setae $c 1-c 3$ are not moved to the lateral sides (Wirth 2004). The detailed study of the distal mouthparts can be useful in the future to discriminate closely related Bonomoia species.

\section{Phylogenetic relationships}

Unlike the bark beetle-clade, possible apomorphies for a Bonomoia-bark-insect-clade consisting of $B$. pini, $B$. spinifera, $B$. certa, and $B$. sibirica are absent (Wirth 2004). B. sibirica shares a number of morphological characters with $B$. certa. These characters are as follows: similar body shapes in the adult females and similar position and size of their ring organs, similar patterns of setae in their dorsal hysterosomas; similar shapes of the dorsal setae on the hysterosomas and palposomas of the deutonymphs and similar patterns of their ventral apodemes. These characters can be interpreted as common apomorphies. Thus, B. certa and B. sibirica might represent sister-species. This hypothesis is supported additionally by ecological circumstances: both are associated with beetles of the genus Dendroctonus.

The females of $B$. spinifer $a$ are dorsally equipped with unusually shaped setae. They are pin-shaped and thus share more similarities with the dorsal setation of $B$. sibirica than to those of $B$. certa or other Bonomoia species. Additionally, setae sce, $c 3, f 2$, $h 1$, and $h 3$ are located on humps as in B. sibirica; the latter also has setae $e 2, c 1$, and sci arranged on bumps, missing in $B$. spinifera. As no other common characters were discovered, there is not enough indication available, whether these few similarities point to a phylogenetic relationship of $B$. spinifera as a sister species of $B$. sibirica $\mathrm{n}$. $\mathrm{sp}+B$. certa. In this case, reductions of the modified dorsal setae in $B$. certa would be a consequence. However, similarities of these two species with $B$. spinifera might also be the result of a convergent evolution.

\section{ACKNOWLEDGEMENTS}

I wish to extend a sincere thanks to Tyumen State University for organizing an excursion to the type locality and for offering me a scientific position.

The present research was completely supported by the grant from the Russian Science Foundation to Tyumen State University, no. RSF
16-14-10109 entitled "Mites associated with bark beetles of main forest-forming coniferous trees of Western Siberia." The grant covered extensive collecting of mites in Siberia and the Far East of Russia and rearing them in the laboratory conditions in Tyumen. I also wish to extend my appreciation to B. OConnor for constructive email discussions about the systematic values of Bonomoia and some related genera.

\section{REFERENCES}

Bongers, M. G. H., OConnor, B. M. and Lukoschus, F. S. 1985. Morphology and ontogeny of histiostomatid mites (Acari: Astigmata) associated with cattle dung in the Netherlands. Zool. Verh. (Leiden), 223: $1-56$.

Fain, A. and Rack, G. 1987. Notes on the mites living in the flowers of Espeletia spp. (Asteraceae) in Columbia. I Carpoglyphus sturmi sp. n. (Acari: Carpoglyphidae). Entomologische Mitteilungen aus dem Zoologischen Staatsinstitut und Zoologischen Museum Hamburg, 9(130), 9-19.

Griffiths, D. A., Ayteo, W. T., Norton, R. A. and Lynch, C. A. 1990. The idiosomal chaetotaxy of astigmatic mites. Journal of the Zoological Society London, 220; 1-32.

Koller L., Wirth S. and Raspotnig G. 2012. Geranialrich oil gland secretions: a common phenomenon in the Histiostomatidae (Acari, Astigmata)? International Journal of Acarology, 38(5-38): 420-426.

Woodring, J. P. and Moser, J. C. 1970. Six new species of anoetid mites associated with North American scolytidae. The Canadian Entomologist, 102(10): 1238-1257.

Scheucher R. 1957. Systematik und Okologie der deutschen Anoetinen. Beitrage zur Systematik und Okologie mitteleuropaischer Acarina, 1: 233-384.

Wirth, S. 2004. Phylogeny, morphology and habitats of the Histiostomatidae (Astigmata). Proceedings of the V Symposium of the European Association of Acarologists. Phytophaga, XIV: 389-407.

Wirth, S. 2005. Description of a new species Bonomoia opuntiae (Histiostomatidae, Astigmata) with observations on the function of its eyes. Acarologia, 45(4): 303-319. http://cat.inist.fr/?aModele $=$ affic heN\&cpsidt $=18276055$

Wirth, S. 2006a. Development of the prelarva and larval behavior to open the eggshell in the Histiostomatidae (Astigmata). Abh. Ber. Naturkundemus. Görlitz, 78(1): 93-104.

Wirth, S. 2006b. Morphology and function of the gnathosoma in the Histiostomatidae (Astigmata). Acarologia, 46(1-2): 103-109. http://cat.inist.fr/? aModele $=$ afficheN\&cpsidt $=18695493$ 
Wirth, S. 2010. Food competition and feeding behaviour and its implications for the phylogeny of the Histiostomatidae (Astigmata). In: Sabelis, M. W. and Bruin, J. (Eds.). Trends in Acarology, 37-40.

Wirth, S. and Moser, J. C. 2010. Histiostoma blomquis$t i$ sp. n. (Acari: Histiostomatidae) A phoretic mite of the Red Imported Fire Ant, Solenopsis invicta Buren (Hymenoptera: Formicidae). Acarologia 50(3): 357-371.
Wirth, S. and Pernek, M. 2012. First record of the mite Histiostoma ulmi in silver fir and indication of a possible phoretic dispersal by the longhorn beetle Acanthocinus reticulatus. Šumarski List, 11-12, CXXXVI: 597-603.

Woodring, J. P. and Moser, J. C. 1970. Six new species of anoetid mites associated with North American Scolytidae. The Canadian Entomologist, 102(10): 1237-1257. 
